\title{
Research on Second Language Vocabulary Acquisition from the Perspective of Cognitive Linguistics
}

\author{
Xianwu Sun \\ ${ }^{1}$ School of Foreign Languages, Northwest Minzu University, Lanzhou, 730030, China
}

Keywords: Second language, Vocabulary acquisition, Cognitive linguistics

\begin{abstract}
Second language vocabulary acquisition is an important composing part of second language acquisition. The prosperous development of cognitive linguistics has provided a new perspective for the studies of second language vocabulary acquisition. This paper starts from the perspectives of cognitive science, discusses the relations between cognitive linguistics and second language vocabulary acquisition, and gives the method of applying cognitive linguistics theory to enhance the teaching of second language vocabulary acquisition, which provides reference for related researchers.
\end{abstract}

\section{Introduction}

Vocabulary ability is the important composing part of language communicative ability. Second foreign language level and ability depends on the volume of vocabulary to great extent. Vocabulary study occupies the important status in the teaching of second foreign language teaching. However, the required huge vocabulary, extensive involved aspects, and low memory efficiency often makes students daunting at the study of vocabulary.

Therefore, in vocabulary teaching, teacher makes the extremely important function to help students tease knowledge and strengthen key points, and use the systematic and interesting methods to instruct vocabulary. Cognitive linguistics is the new language linguistics prospered in America and Europe in the 1980s, which is at the frontier of language research field at home and abroad, mainly concentrated on the theory of cognitive linguistics. It provides the new perspective for learners and researchers and develops the large function on numerous aspects of vocabulary, syntax, semantics and so on.

With the deepening and maturity of the theoretical research of cognitive linguistics, its research achievements have been continuously applied to second language acquisition and foreign language teaching, so as to explain and solve the problems appearing in second language acquisition and foreign language teaching and the psychological status of learners while studying the second language. However, vocabulary is the composing part of language, the most fundamental component, so learners should do the most basic vocabulary acquisition well for the future acquisition bedding.

This paper mainly takes the study strategies of vocabulary acquisition and its depth and width as the goal, applies the major theoretical application of cognitive linguistics to second language vocabulary acquisition, and expects to largely increases the efficiency of second language vocabulary acquisition. This paper mainly studies the effects of cognitive linguistics theory on second language vocabulary acquisition, including the function and application methods of categorization theory, prototype theory and schema theory on second language vocabulary acquisition.

\section{Common Theories of Cognitive Linguistics}

Categorization Theory.The proposal of cognitive linguistics categorization theory has provided the new perspective for the second language acquisition research. Categorization theory is a dynamic theory, a process in recognition, and categorization theory is the core and foundation of cognitive linguistics discipline. "It refers to similarity that humans have seen in the different reality, and different recognizable things can be disposed as the same on this basis. Everything in the world is 
classified on this basis, so as to form the process and ability of concepts", that is to say, humans will classify things consciously in the process of recognizing things, and this divided category is a categorization, such ability of people to classify is the categorization ability. For example, people will categorize beds, chests, bookshelf as the furniture.

Therefore, categorization is the reflection of the recognition subjects on the concept of their thinking on the basis of external thing experience. Categorization has provided an effective tool for humans to recognize the world so that teachers can help students conclude and summarize vocabulary according to different vocabulary categories. While teachers are instructing new words, they can firstly review some related words that students have mastered, and then analyze the origin relations between the both in word-building. Once students understand such origin relations, it will be very easy to memorize new words. After they are familiar with new words, it will be become the new starting point of memory. By parity of reasoning, the entire memorization process is a screw-type roaring and increasing sharply in multiple times like snow ball rolling. Knowing vocabulary and producing associations is one of very important means to expand the vocabulary volume. In fact, all word-building methods fit certain recognition rules, and combining rules and word-building to interpret words will achieve double effects.

Prototype Theory.Prototype theory is the theory about category. This theory is based on the experiences and observation of the objective world, and it provides the new proper methods for the division and property of category. It has been a very long history for the research of category. From Aristotle to Wittgenstein period, "classical theory" of category or the so-called "Aristotle theory" rules all the world. In this theory, it is believed that category is defined by the united necessary and sufficient characteristics. Category has the specific boundary, and the status of all members within the category is equal. However, this theory suffers from the powerful challenge of pragmatism philosophy. The basic opinions of category views in modern prototype theory are summarized as below. There are typical and non-typical category members, and subordinating degree of the both differs. Similarity and common characteristics exist among category members, which can compose a continuity. The boundary of category is vague.

The information that the external world provides us is not mussy, but there are rules to follow. Some basic objects with significant characteristics compose the basic level of category. On this basis, there are more abstract and summarized high level of category. Within the basic level of category, there are relatively specific and less summarized low level of categories. Language is not completely the formal thing, nor a set of rule system. It is the auxiliary tool and expression means for humans to recognize the world. It reflects how humans categorize and conceptualize the objective world. The high level of category, basic level of category and low level of category consist of the grade structure of language. We recognize and interpret the world through this structure. The basic unit of the language-word associates with numerous means. Vocabulary is stored in the memory by a huge complex relationship net. It can be seen that prototype category theory equips with certain constructive meaning to vocabulary study.

Schema Theory. While readers are discussing the relations between schema theory and second language reading, schema is usually divided into three types: formal schema, content schema and language schema. Formal schema includes the article style, structure and other contents. Content schema include article theme, target language culture and so on. Language schema includes language knowledge, vocabulary knowledge and other contents. These three schemas are vitally important for readers to comprehend reading materials.

However, readers cannot equip with the three in most of occasions, or some schema cannot be fully activated by some reason. In this situation, existing or activated schema will correspondingly supplement the defective schema. In fact, various kinds of schema are stored in the brain of humans, such as things, events, scenarios, activities and so on. These schema forms the recognition and understanding of world, or the so-called "encyclopedic knowledge". The quantity of these schema is huge, and the graduation is complex, but they are all organized and arranged systematically according to the certain system, any of them associates with other members or the members of other themes directly or indirectly through this or that means, so as to form an interweave stereoscopic close 
relationship network. Every time when new knowledge system enters the brain, it will form its own new schema, finally recombined, integrated and compiled into such a huge network. Therefore, when people need to recognize and handle the new information from the outside, some schema in the network will be activated and mobilized by this new information, so as to explain, analyze, organize and absorb it, finally internalized into the total schema and become its one hierarchy.

\section{Second Language Vocabulary Acquisition Based on Cognitive Linguistics}

Second Language Vocabulary Acquisition Based on Categorization Theory.The categorization theory of cognitive linguistics mainly includes prototype categorization theory and basic level of categorization theory. These two theories are greatly helpful to second language vocabulary acquisition and teaching. The basic level theory is reflected in the synchronous process of category formation, and the vocabulary category also produces. In the meantime, the sequence of vocabulary production and development also appears. The basic level category vocabulary includes the upper category vocabulary and subordinate category vocabulary. The basic category of vocabulary makes the important function from the basic level of superior vocabulary and the subordinate level of vocabulary.

There are three kinds of hierarchy structure: basic level category, superior category and subordinate category. The basic level of category is the powerful weapon for categorization, the most direct aspect for people to recognize things. In vocabulary, the basic level of category is common use words with single syllables, easy to match and build words, and their basic meaning can be expanded. However, superior and subordinate category is not like this, because they are parasitic categories. Category hierarchy structure theory makes the important function in the second language acquisition's vocabulary study. In the process of teaching second language vocabulary acquisition, teachers can put English words with similar meaning, characteristics, properties and categories together according to superior and subordinate category theories, gather their meanings together, predicts the extension to exceed superordinate, so as to establish the teaching method of vocabulary network, classify the vocabulary and build a vocabulary network with the basis of the most bottom of vocabulary. Vocabulary is stored in the brain with interactive association in the form of the network, and the forms, meanings and functions of words are easy to remember.

Second Language Vocabulary Acquisition Based on Prototype Theory.Prototype is the typical member in a category, which can reflect the most typical characteristics of this category. Other members and prototypes in this category can perceive the similarity and become the member of this category. The status of members in the category is not equal. That is to say, the similarity degree of every member with the typical member is not equal, and the typical member is the prototype. The prototype is the most perfect and the best member when it comes to some category characteristic, which is decided by the judgment of humans.

The typical property of prototype refers to the vocabulary with the highest appearance or use frequency in the category, or the concept prototype is the most typical in the semantic category, always firstly known by people. In the teaching of second language vocabulary, the polysemy phenomenon should be started from the prototype theory.

On the basis of familiar typical meanings of polynemas words, teachers can instruct students to learn other meaning, make students remember all meanings, and it is not easy to forget. In cognitive science, it is believed that our recognition and perception of external things start from the most typical thing-prototype. Therefore, learners should firstly study prototype vocabulary or the prototype meaning of words. In addition, prototype model has the powerful explaining power to classification events. Prototype category consists of prototype and edges. Prototype is the typical member of this category, but edge is the non-typical member. People usually firstly know the prototype vocabulary or its prototype meaning. On this basis, according to family similarity theory, edge vocabulary can be known. Therefore, in the teaching of second language vocabulary acquisition, learners should firstly learn prototype vocabulary, and teachers should teach it firstly. On the basis, teachers introduce the abstract meaning of prototype vocabulary, and make learners learn more vocabulary and meanings. 
Second language Vocabulary Acquisition Based on Schema Theory.Schema is a kind of recognition means and framework, which provides the sufficient reference and evidence for people's forecast, understanding and other recognition activities, so as to process, handle and store the external new information.

Therefore, we have absolute reasons to believe that schema is the basis of all recognition activities. The processing and treatment of all information should be based on schema, because when people know new things, they always associate them with the concepts and experiences they have known for the convenience of understanding. In second language vocabulary acquisition, word is also a schema. Second language learners should firstly learn certain quantities of basic vocabulary, so as to form the certain scale of vocabulary schema. Learners are able to master certain vocabulary knowledge, such as word meaning, syntax characteristics, usage habits, so as to further enrich and improve existing vocabulary schema, constantly apply it to predict, recognize and process the new acquired structural form of vocabulary knowledge, so as to promote the coding of these new words in the long-term memory storage of learners.

Once the coding process of these words is completed, they will be also internalized into the brain of learners, and vocabulary recognition schema is not easy to forget. With the continuous development and expansion of vocabulary schema, the efficiency of vocabulary acquisition has also continuously improved, and the new acquired vocabulary will be easier. For learners with the relatively complete vocabulary schema development, the volume of vocabulary is relatively larger, they have mastered certain vocabulary knowledge and equip with certain vocabulary abilities, so their coding abilities of syntax and chapters are stronger. In this scenario, he is able to distribute redundant recognition resources to other missions, such as collateral acquisition of new words.

\section{Conclusion}

Second language vocabulary acquisition is the basis to learn the second language. This paper describes the specific contents of categorization theory, prototype theory and schema theory in cognitive linguistics, regards it as the guidance, and discusses the new concepts of second foreign language vocabulary teaching. Applying cognitive linguistics theory to the second foreign language's vocabulary teaching can improve the study interest of students, improve the class atmosphere and increase the teaching quality.

\section{References}

[1] Yu Cuihong, Liu Jianfu. New trends of SLA research paradigms under the framework of cognitive linguistics [J].Modern Foreign Languages (Bimonthly), 2015, 38(6): 833-841+874.

[2] Lin Baozhu. The Study of Dispelling Fossilizationin L2 Vocabulary Acquisition: A Cognitive Linguistic Approach [J].Journal of Hunan Institute of Engineering, 2012, 22(2): 40-44.

[3] Wang Zhen, Wang Fang. A New Approach to Second Language Teaching-A Review of Applying Cognitive Linguistics to Second Language Learning and Teaching [J]. Overseas English, 2014(10): 255-257.

[4] Verspoor M H. Cognitive Linguistics and Its Applications to Second Language Teaching[J]. Language Awareness and Multilingualism, 2016: 1-12.

[5] De Knop S, Meunier F. The 'Learner Corpus Research, Cognitive Linguistics and Second Language Acquisition'nexus: a SWOT analysis[J]. Corpus Linguistics and Linguistic Theory, 2015, 11(1): 1-18.

[6] Zeng Jun, Lu Fangzhe. CognitiveLinguistics and TeachingChineseasaSecondLanguage [J].Journal of Yunnan Normal University (Teaching and Research on Chinese As A Foreign Language), 2013, 11(1): 1-9. 